\title{
Thermal Plasma Processes for Production of Hollow Spherical Powders: Theory and Experiment*
}

\author{
Oleg P. SOLONENKO**, Igor P. GULYAEV** and Andrey V. SMIRNOV** \\ **Khristianovich Institute of Theoretical and Applied Mechanics SD RAS, Novosibirsk 630090, Russia \\ E-mail: solo@itam.nsc.ru
}

\begin{abstract}
Present paper considers processes of production and treatment of hollow particles in plasma flows. Specifics of agglomerated powders treatment and expansion of hollow droplets are analyzed theoretically. Experimental results on production of hollow micro particles of $\mathrm{ZrO}_{2}, \mathrm{Ni}, \mathrm{CoNiCrAlY}$ alloy, $\mathrm{SiO}_{2}$ are shown here.
\end{abstract}

Key words: Plasma Spraying, Hollow Spheres, Agglomerated Powders, Suspension Spraying, Zirconia

\section{Introduction}

In the present-day industry of structural and protective materials, powders made up by hollow spheres, or hollow powders, gain increasing acceptance. Hollow ceramic powders are used in the production of plasma-sprayed thermal barrier coatings, composite heat- and sound-insulating materials, light construction fillers and backfills, buoyancy materials, and explosive mixtures. Such powders also form basis for catalysts, adsorbents, filter elements, encapsulating media, etc. Application of hollow powders has entered a stage at which the range of scientific and engineering problems to be solved widens permanently; in this connection, guaranteed synthesis of hollow microspheres with desired morphology, chemical composition, and mechanical properties becomes an urgent matter.

An analysis of publications presented at major international conferences and in leading foreign and Russian journals shows that, presently, issues concerning the formation of hollow microspheres and the behavior of such microspheres in plasma flows receive insufficient attention.

The main necessary condition to form a hollow particle in plasma flow is sufficient gas content in feedstock powder material. This can be obtained by application of porous particles, binders in agglomerates which evaporate at high temperatures, powders with high specific surface area providing gas adsorption, etc. Our experiments with zirconia powder show that gas to material (particle) mass ratio $\mathrm{m}_{\mathrm{g}} / \mathrm{m}_{\mathrm{p}} \sim 10^{-4}$ at room temperature and $\mathrm{m}_{\mathrm{g}} / \mathrm{m}_{\mathrm{p}} \sim 10^{-5}$ at melting point is enough to produce hollow spheres with shell thickness about $10-20 \%$ of particle diameter. When such particles enter a plasma flow melting starts at their surface forming a liquid film which catches residual gas. Further heating of a liquid spheres leads to expansion and consolidation of gas cavities and surface tension provides spherical shape of inner void. After a liquid hollow sphere leaves plasma jet and solidifies a position of a gas cavity is fixed and generally it is in the center of the particle, providing uniform shell thickness.

Over the recent decade, in connection with ever increasing interest to hollow powders and widening application field of such powders, considerable efforts of researchers have been focused on the development of new approaches to the problem of formation of hollow

[DOl: 10.1299/jtst., 2011 (No. 11-0074)

Copyright $@ 2011$ by JSME 
microspheres in thermal plasma.

The present publication is intended to give an overview of our results that were obtained in recent years in the Laboratory of plasma dynamics and energy conversion in dispersed systems, ITAM SB RAS, in the field of processing various agglomerated powder materials in plasma in the context of obtaining hollow spherical metal, alloy, and oxide-ceramic powders.

\section{Analysis of plasma processes involving agglomerated particles}

As it was noted in [1], a simplest production method of hollow powders implies processing of void-free, or dense, particles in plasma. For instance, for a number of materials such as oxides their densities $\rho_{p}^{(s)}$ and $\rho_{p}^{(l)}$ in the solid $(s)$ and liquid $(l)$ state may differ substantially. As a result, a particle with $\rho_{p}^{(l)}<\rho_{p}^{(s)}$, as it melts, grows in volume, so that its efficient size increases. The radius of a fully molten particle increases by

$$
\Delta R_{p}=R_{p 0}\left(\sqrt[3]{\rho_{p}^{(s)} / \rho_{p}^{(l)}}-1\right)
$$

where $R_{p 0}$ is the initial particle radius. An overheated melt droplet subsequently given a quench, its solidification starts from the surface, so that the particle size turns out to be fixed at $R_{p s}=R_{p}+\Delta R_{p}$. Following crystallization-induced volume shrinkage, a spheroidal cavity forms inside the particle, the relative radius of the cavity being $R_{h}=R_{p 0}+\Delta R_{p}-h$ and the shell thickness

$$
h=R_{p s}\left[1-\sqrt[3]{1-\left(R_{p 0} / R_{p s}\right)^{3}}\right] .
$$

With the obtained dependences at hand, we can obtain numerical estimates for $\alpha-\mathrm{Al}_{2} \mathrm{O}_{3}$ (corundum) particles. Analyzing available experimental data, the authors of [2] proposed the following dependence for the corundum density in liquid state: $\rho_{p}^{(l)}(t)=3030-1.08(t-2054)$, where the dimensions of density are $\mathrm{kg} / \mathrm{m}^{3}$, and the dimensions of temperature $t$ are Celsius degrees. For the density of corundum in solid state, we adopt a value $\rho_{p}^{(s)}=3960 \mathrm{~kg} / \mathrm{m}^{3}$. Then, for a droplet of radius $50 \mu \mathrm{m}$ at the melting point $T_{p m}=2054^{\circ} \mathrm{C} \quad$ we have: $\rho_{p}^{(l)}\left(2054^{\circ} \mathrm{C}\right)=3030 \quad \mathrm{~kg} / \mathrm{m}^{3}, \quad \Delta R_{p} \approx 4.7 \mu \mathrm{m}$, $R_{p}+\Delta R_{p} \approx 54.7 \mu \mathrm{m}, h \approx 20.9 \mu \mathrm{m}$, and $R_{h} \approx 33.8 \mu \mathrm{m}$.

For the same droplet overheated over the melting point by $400^{\circ} \mathrm{C}$, we similarly obtain: $\rho_{p}^{(l)}\left(2454^{\circ} \mathrm{C}\right)=2598 \mathrm{~kg} / \mathrm{m}^{3}, \Delta R_{p} \approx 7.5 \mu \mathrm{m}, \quad R_{p}+\Delta R_{p} \approx 57.5 \mu \mathrm{m}, \quad h \approx 17.3 \mu \mathrm{m}$, and $R_{h} \approx 40 \mu \mathrm{m}$.

Hence, the characteristics of hollow spheres solidified from overheated molten dense particles are fully defined by the densities of the particle material in the solid and liquid state, and also by the overheating value of the droplets. Provided that the particle shell is impermeable, a spheroidal vacuum cavity forms inside each particle.

However wider practical possibilities of production of hollow particles can be provided by plasma treatment of agglomerated powders. Several methods for obtaining agglomerated powders with particle sizes in the range of several ten micrometers whose particles comprise several uniformly mixed nano-, submicro-, or micro-sized powder components are presently known. Those methods include: (i) extrusion, (ii) spray drying, (iii) processing of sprayed suspensions and solutions in plasma, (iv) electrolytic deposition of materials, (v) mechanical activation of powder mixtures in high-energy planetary ball mills, etc.

Conditions for obtaining hollow microspheres. Agglomerated particles normally have a heterogeneous structure and a porosity $p$, which, as a rule, is open-type porosity. However, whatever the production method of particles, their treatment in thermal plasma aimed at obtaining microspheres has many features in common; such a treatment normally comprises the following stages (see Fig. 1):

1) heating of solid particles till the moment the melting point is reached at the particle 
surface and a surface melt layer forms there; during this stage, the gas initially contained in the pore space of particles, as it thermally expands, partially leaves the material in the filtration regime;

2) arresting of the remainder gas in the particle as the particle further melts, and subsequent formation of an internal gas cavity and a liquid spherical shell;

3) quenching of obtained hollow droplets, resulting in the formation of hollow microspheres.

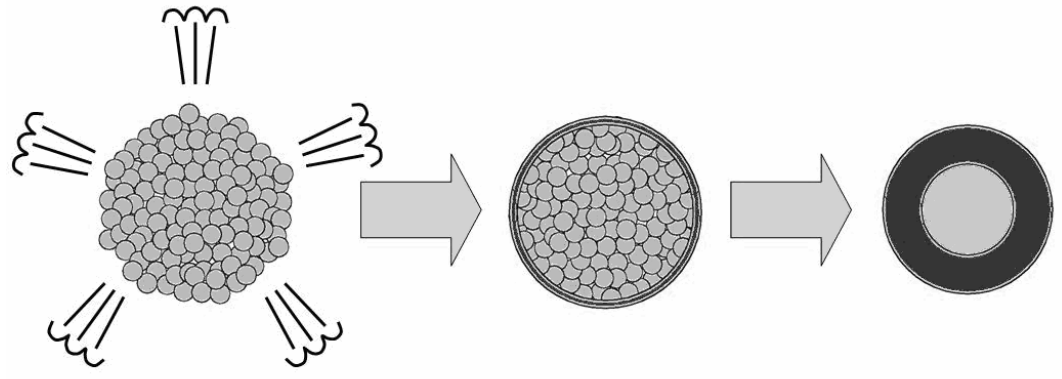

Fig. 1. Formation scenario of a hollow particle.

It is worth noting that, in treating agglomerated ceramic, metal, or alloy particles, and also gas-rich metal powders, in plasma, depending on the heating intensity, or density of the heat flux, formation of hollow particles or particles whose volume contains distributed spherical gas cavities is possible.

In this connection, we introduce the following characteristic times: (i) the thermal relaxation time $t_{a}=R_{p}^{2} / a_{p}^{(s)}$, which defines the rate of equalization (leveling) of the temperature field inside a particle heated from the surface (here, $a_{p}^{(s)}$ is the heat diffusivity) and (ii) the time $t_{q m}=\rho_{p}^{(s)} c_{p}^{(s)}\left(T_{p m}-T_{p 0}\right) R_{p} / q$, which defines the thermal susceptibility of particle material to the heat supplied to the particle surface at the stage of heating of the surface from an initial temperature $T_{p 0}$ to the melting point $T_{p m}$. The ratio of the two characteristic times,

$t_{a} / t_{q m}=R_{p} q / \lambda_{p}^{(s)}\left(T_{p m}-T_{p 0}\right)$,

defines the regime of particle heating in plasma. In principle, two heating regimes are possible: gradient heating $-t_{a} / t_{q m}>1$, and uniform heating $-t_{a} / t_{q m}<1$.

By analogy, one can introduce a dimensionless parameter $L_{q m}=\lambda_{p}^{(s)}\left(T_{p m}-T_{p 0}\right) / q$, which defines the characteristic spatial scale of heat transfer during the heating of the particle surface to the melting point at a given heat flux density. If $L_{q}<<R_{p}$, then we have a gradient heating, proceeding with the formation of a melted layer on the particle surface as the surface temperature reaches the melting point, whereas the particle interior still remains cold. Here, the continuous melt film formed on the surface arrests the gas contained in the pore space of the particle; as a result of complete melting of the particle, there forms a spherical droplet, which, as it solidifies from the surface, forms a hollow microsphere. On the contrary, if $L_{q}>R_{p}$, then the particle undergoes a gradientless, or uniform, heating. Here, as the particle temperature reaches the temperature $T_{p m}$, the particle melts uniformly throughout its volume; as a result, suspended gas bubbles remain in the melt, which, on droplet solidification, lead to the formation of microspheres with a distributed closed-type porosity.

This analysis can also be applied to evaluating the possibility of obtaining hollow microspheres from agglomerate particles with a heterogeneous internal structure (particles obtained by spray drying, mechanocomposite particles, particles obtained by plasma treatment of atomized suspensions of the 'liquid - solid inclusions' type, etc.). As a result of the analysis, requirements to the operating regime of the plasma torch and requirements to 
the working-gas composition are to be formulated.

Evolution of hollow droplets during variation of their temperature and ambient pressure. To proceed with further analysis, consider a simplest formation scenario of a hollow particle based on an assumption of open-type porosity of the initial agglomerate and no disintegration of agglomerate particles occurring during treatment. As an agglomerated particle of diameter $D_{p 0}$ enters a plasma jet, both the particle material and the gas contained in the pore space of the particle undergo an intense heating (Fig. 1). On expansion, some amount of the gas initially contained in the particle leaves the particle volume, the pore volume $V_{g 0}$ remaining unchanged. At the moment the particle surface reaches the temperature $T_{p m}$, on the surface of the agglomerated particle a melt film forms, which defines the arrested gas mass $m_{g 0}$. The gas arrested by the thickening shell is forced towards the center of the particle and, on completion of particle melting, it takes a central position, forming an isolated cavity whose size is defined by the droplet temperature and ambient pressure. Let us calculate now the outer diameter of the formed hollow droplet $D_{p 0}$ and the relative shell thickness in it, $\delta_{p 0}=\Delta_{p 0} / D_{p 0}$. With $p$ being the initial particle porosity, the total volume of the pores in the particle is $V_{g 0}=\pi p D_{p 0}^{3} / 6$, and the gas mass arrested in the particle at temperature $T_{p m}$ is $m_{g 0}=\rho_{g}\left(T_{p m}, P_{g 0}\right) V_{g 0}$, where $\rho_{g}$ is the gas density at the initial temperature and pressure.

Subsequent state of the gas volume in the hollow droplet obeys the Mendeleev-Clapeyron equation

$P_{g} V_{g}=\frac{m_{g 0}}{M_{g}\left(T_{g}, P_{g}\right)} R T_{g}$.

Here, $V_{g}=\frac{4 \pi R_{p}^{3}}{3}\left(1-\frac{\Delta_{p}}{R_{p}}\right)^{3}$ is the current gas volume after the complete melting of the particles and its heating to a temperature $T_{g}>T_{p m}, R$ is the universal gas constant, and

$M_{g}$ is the temperature- and pressure-dependent molar mass of the gas. As a result, equation

(2) takes the form

$P_{g}=\frac{3 m_{g 0} R T_{g}\left(1-\Delta_{p} / R_{p}\right)^{-3}}{4 \pi R_{p}^{3} M_{g}\left(T_{g}, P_{g}\right)}$.

In view of (3), we can write the following equation of pressure balance at the droplet surface, which relates the equilibrium droplet radius and the equilibrium shell thickness:

$P_{f 0}+\frac{2 \sigma_{p}}{R_{p}} \cdot\left(1+\frac{1}{1-\Delta_{p} / R_{p}}\right)=\frac{3 m_{g 0} R T_{g}\left(1-\Delta_{p} / R_{p}\right)^{-3}}{4 \pi R_{p}^{3} M_{g}\left(T_{g}, P_{g}\right)}$.

Here, $P_{f 0}$ is the ambient pressure, and $\sigma_{p}$ is the melt surface tension coefficient.

Finally, with the additional condition of constant mass of the liquid shell, we obtain:

$m_{p 0}=\frac{4 \pi \rho_{p} R_{p 0}^{3}}{3} \cdot\left[1-\left(1-\Delta_{p 0} / R_{p 0}\right)^{3}\right]$, so that $1-\Delta_{p} / R_{p}=\sqrt[3]{1-\frac{3 m_{p 0}}{4 \pi \rho_{p} R_{p}^{3}}}$.

Thus, solving equation (4) under condition (5), we obtain the current value of the radius $R_{p}$ and, then, the shell thickness $\Delta_{p}$ for given particular conditions.

Figure 2 shows the calculated values of the outer diameter (a) and relative shell thickness (b) of hollow microsphere versus the size of the initial agglomerated particle. The calculations were performed for $\mathrm{ZrO}_{2}$ particles of various initial porosities processed in atmospheric-pressure air plasma. In the calculations, data of [3] for air properties were used. It is seen that the outer diameter of the obtained hollow droplet $D_{p}$ is roughly the size of 
the initial agglomerated particle $D_{p 0}$ (the former diameter is 2-10\% smaller than the latter one), and it is almost independent of the porosity of the initial powder $p$ in the porosity range $p=0.2 \div 0.7$. Simultaneously, the initial porosity has a pronounced effect on the relative shell thickness $\delta_{p}$.

Figure 3 shows data that illustrate the dependence of particle shell thickness on the initial porosity of the powder for particles of various diameters $D_{p}$. It is seen that in the considered range of particle sizes the shell thickness almost linearly decreases with increasing porosity.

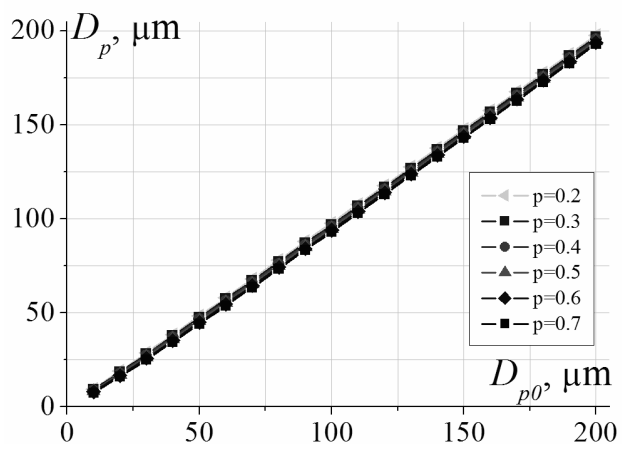

(a)

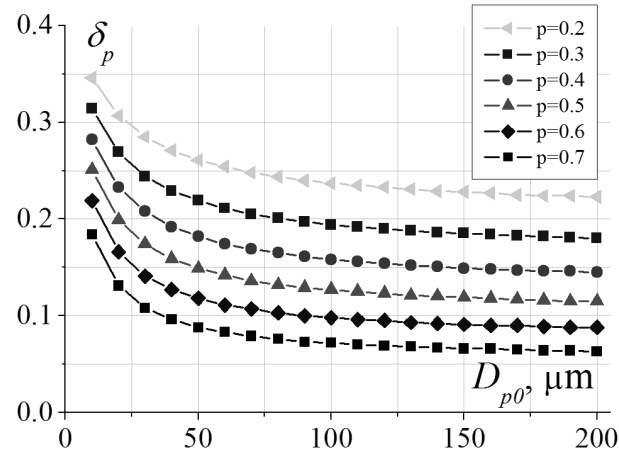

(b)

Fig. 2. Diameter (a) and relative shell thickness (b) of hollow particle versus the size of the initial $\mathrm{ZrO}_{2}$ agglomerate.

The calculated data presented in Figs. 2 and 3 can be used in determining the characteristics of an initial agglomerated powder to be used for obtaining hollow particles of a desired morphology.

A comparison of predicted shell thicknesses of $\mathrm{ZrO}_{2}$ hollow spheres with measured shell thicknesses is shown in Fig. 4. In the calculations, an experimental estimate of the porosity of the initial agglomerates, $p=0.45$, was used.

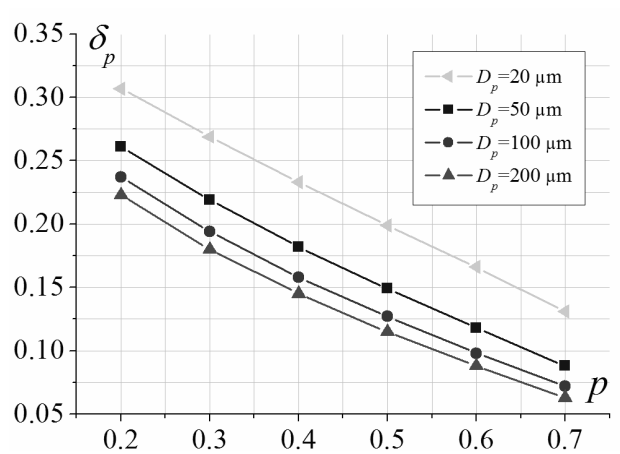

Fig. 3. Shell thickness of formed hollow particle versus the initial porosity of particle agglomerates.

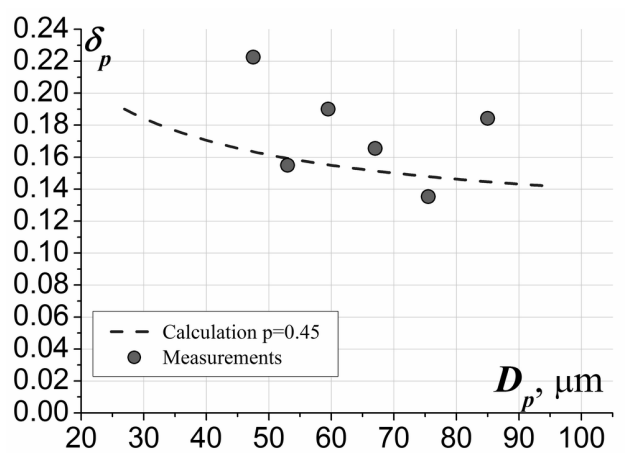

Fig. 4. Shell thickness versus particle size.

It can be concluded that, in a first approximation, the proposed model for the formation of hollow particles well agrees with experimental data: the root-mean-square deviation here is $18 \%$, while the higher measured values of shell thickness could be a consequence of either some fraction of dense particles present in the obtained powder, or particle fragments resulting from disintegration of hollow particles. 


\section{Production of hollow microspheres in thermal plasma}

\subsection{Processing of powders obtained by spray drying}

As it was noted above, several processes are known suitable for production of hollow particles in thermal plasma. An efficient method here is plasma processing of agglomerated powders obtained by spray drying. A unique material for spraying thermal-barrier and heat-resistant coatings is zirconia stabilized by yttria. The use of a hollow $\mathrm{ZrO}_{2}$ powder allows one to ease the requirements to plasma facilities and, simultaneously, improve the heat-resisting capability and strength characteristics of sprayed coatings [4, 5].

In tests aimed at obtaining hollow $\mathrm{ZrO}_{2}$ microspheres it was found that the morphology of such microspheres was largely defined by preparation conditions of the initial agglomerated powder, and also by the thermal and gas-dynamic characteristics of used plasma flows [6-8].

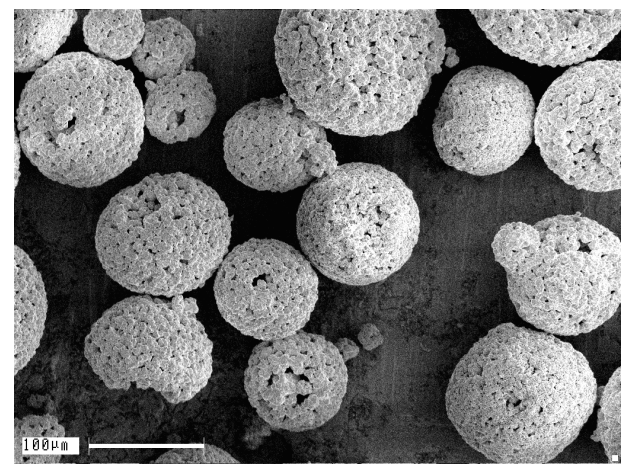

Fig. 5. External appearance of the initial $\mathrm{ZrO}_{2}$ powder.

Figure 5 shows a SEM image illustrating the external appearance of the initial $\mathrm{ZrO}_{2}$ powder obtained by the spray drying technique. It is seen that the powder particles range in size from 50 to $150 \mu \mathrm{m}$. Here, the sizes of individual microparticles forming the agglomerates cover the range from 3 to $5 \mu \mathrm{m}$, with the total number of the microparticles in a single agglomerated particle being $10^{3}-10^{5}$. The mean volume porosity of the initial powder is $p=0.45$, the gas-to-particle mass ratio at room temperature being at a level $m_{g} / m_{p} \approx 2 \cdot 10^{-4}$, whereas at the melting point of the material $\left(T_{p m}=2960 \mathrm{~K}\right), m_{g} / m_{p} \approx 2 \cdot 10^{-5}$.

All other conditions being identical, the morphology of plasma-processed powders is largely defined by the thermal and gas-dynamic characteristics of the plasma torch. In this connection, we performed a comparison of characteristics of hollow spherical powders obtained by processing the initial powder in the plasma jet of a linear plasma torch and a two-jet plasma torch (Fig. 6).

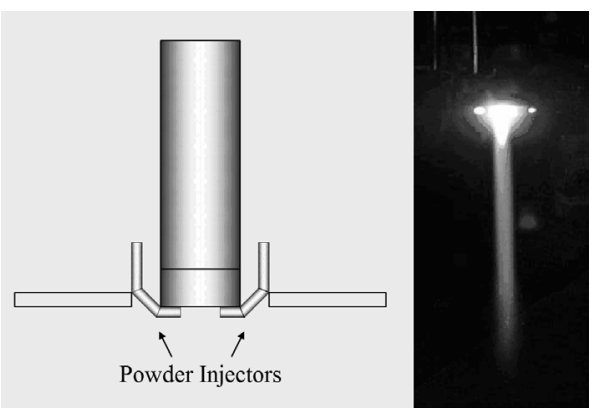

(a)

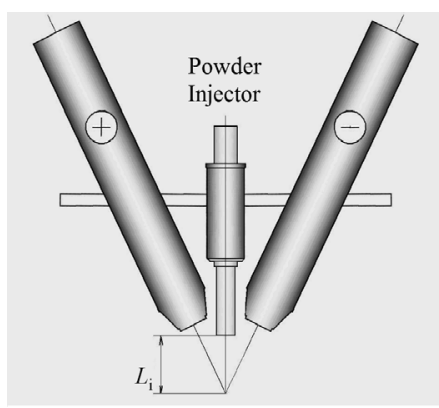

(b)

Fig. 6. Diagram of powder injection into the plasma jets and the general appearance of the plasma flows: linear plasma gun with radial powder injection (a), two-jet plasma gun with axial powder injection (b).

The thermal power of the nitrogen plasma flows in both cases was about $45 \mathrm{~kW}$, and the powder processing capacity, $20 \mathrm{~kg} /$ hour. The operating regime of the linear plasma torch with inter-electrode inserts (IEI) was as follows: working gas feedrate $2 \mathrm{~g} / \mathrm{s}$, exit nozzle diameter $14 \mathrm{~mm}$, arc current $250 \mathrm{~A}$, arc voltage $310 \mathrm{~V}$, thermal efficiency $60 \%$. This provided 
gas enthalpy about $23 \mathrm{~kW} / \mathrm{g}$, which means that average plasma temperature at nozzle exit was about $7000 \mathrm{~K}$, and velocity about $380 \mathrm{~m} / \mathrm{s}$. The powder was injected into the plasma jet along the radius into the region under the plasma-gun nozzle exit (Fig. 6, a). The two-jet plasma torch was operated at $0.3 \mathrm{~g} / \mathrm{s}$ nitrogen feedrate into each of the electrode units, arc current $200 \mathrm{~A}$, arc voltage $250 \mathrm{~A}$, thermal efficiency $90 \%$. Average plasma temperature can be evaluated if no thermal power loss is considered: gas enthalpy $75 \mathrm{~kW} / \mathrm{g}$ and gas temperature about $12000 \mathrm{~K}$. In the case of the two-jet plasma torch the powder was injected into the region located at a distance $L_{i}=25 \mathrm{~mm}$ from the merging zone of the electroconductive jets (Fig. 6, b).

In the case of the linear plasma gun, the processed powder proved to be substantially finer than the initial powder: here, the mean particle size was about $20 \mu \mathrm{m}$, with almost no fractions coarser than $60 \mu \mathrm{m}$ being present in the processed powder (Fig. 7, a). This result clearly indicates that, during the treatment, the initial agglomerates underwent disintegration. In the latter case of the two-jet plasma gun the mean particle size was about $45 \mu \mathrm{m}$, the size distribution of particles was more homogeneous, i.e. broader, with an appreciable amount of particles with sizes in the range from 10 to $85 \mu \mathrm{m}$ being present in the powder (Fig. 7, b).
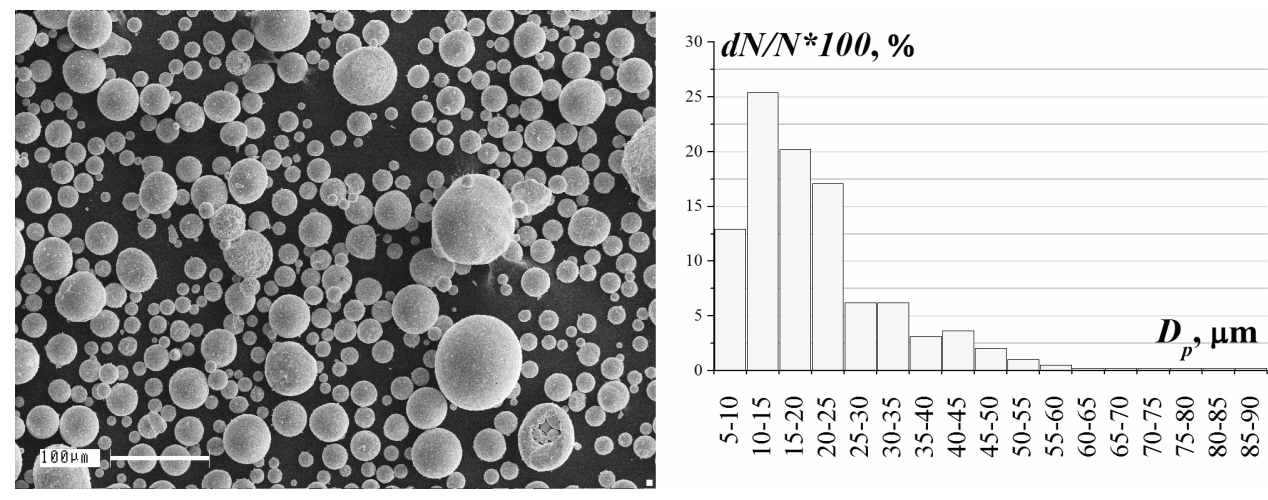

(a)
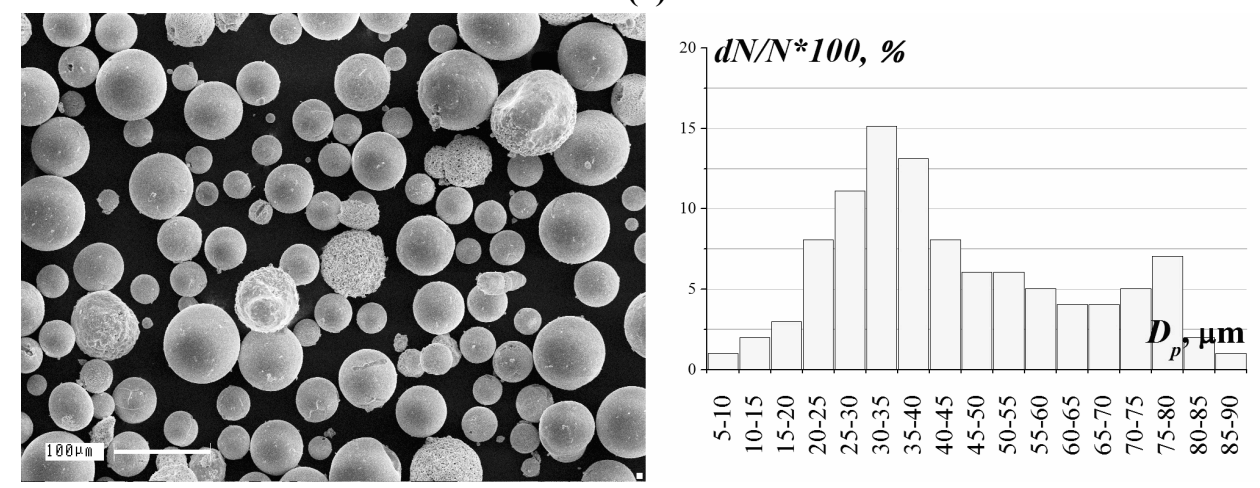

(b)

Fig. 7. External view and size distribution of $\mathrm{ZrO}_{2}$ powder particles processed in the plasma jet of the linear (a) and two-jet (b) plasma torch.

The latter results can be explained by the following factors. First, during processing in plasma the initial agglomerated powder particles experienced mechanical stresses resulting from the high temperature and high heating rate; those stresses included (i) the thermal stress induced by the non-uniform thermal expansion of the agglomerate owing to the temperature gradient and (ii) the baric stress induced by the increasing pressure due to the gas and organic binder vapors contained in the pore microvolumes. The amount of the residual gas arrested in the hollow sphere was defined by the gas losses in the agglomerate 
owing to the radial filtration flow, which ceased at the moment a continuous outer melt film formed on the agglomerate surface.

Thus, the agglomerated particles of the initial $\mathrm{ZrO}_{2}$ powder at their radial injection into the plasma torch (case 1) suffered considerable thermal and baric stresses since the mass-mean temperature of the nitrogen plasma at the nozzle exit plane of the plasma gun was about $8000 \mathrm{~K}$ (Fig. 8). As a result, the initial particles could disintegrate into several smaller agglomerates, which then passed a spheroidization stage. In the second case, prior to entering the merging zone of the conducting jets the particles experienced rather a soft radiative-conductive heating. As a result, the most probable scenario before the moment the particles entered the hot zone included sintering of microparticles contained in each initial agglomerated powder particle; the sintered agglomerates then entered the mixing zone of the conducting jets, or the hot zone. Under such a heating regime, agglomerates normally display less pronounced tendency to disintegration.

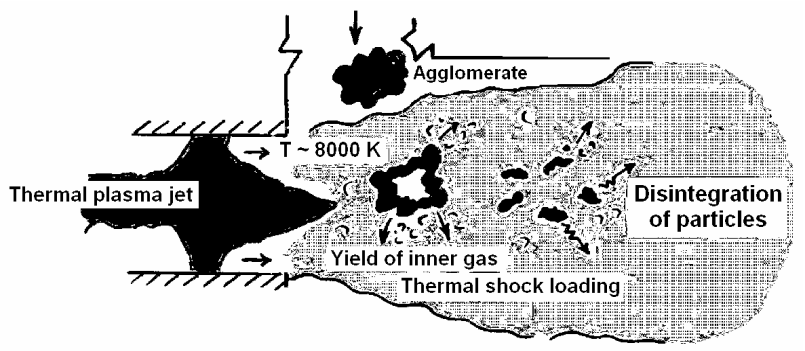

Fig. 8. Diagram of the disintegration process of an agglomerated particles in the plasma torch (schematically).

Second, two other factors deserve mention which could lead to disintegration of already formed hollow melt droplets, and, hence, to a reduced mean particle size of the final spherical powder. Those factors, provoking disintegration of hollow droplets into fragments, which then underwent spheroidization and in-flight solidification, are the following:

- dynamic pressure, acting on the hollow droplet from the side of the gas carrier flow owing to the considerable velocity difference between the particle and the plasma flow;

- heating of the gas contained inside the already formed hollow liquid particle, leading to an increase of its internal pressure, an increase of the outer diameter, thinning of the shell, and shell fracture.

As far as our knowledge goes, those problems as applied to hollow droplets so far have never been considered in the literature, and they call for further investigation.

A comparison of the hollow $\mathrm{ZrO}_{2}$ powder obtained in our experiments with a commercially available hollow powder is given in Fig. 9. It is seen that the particles in the produced powder (see Fig. 9, a) were shaped as regular spheres and, in contrast to those in the commercial powder (see Fig. 9, b), were all hollow particles. The commercial powder contained a large fraction of non-hollow particles, a considerable fraction of agglomerated particles in it had not passed complete treatment, and the shell thickness in the hollow particles varied over a wide range.
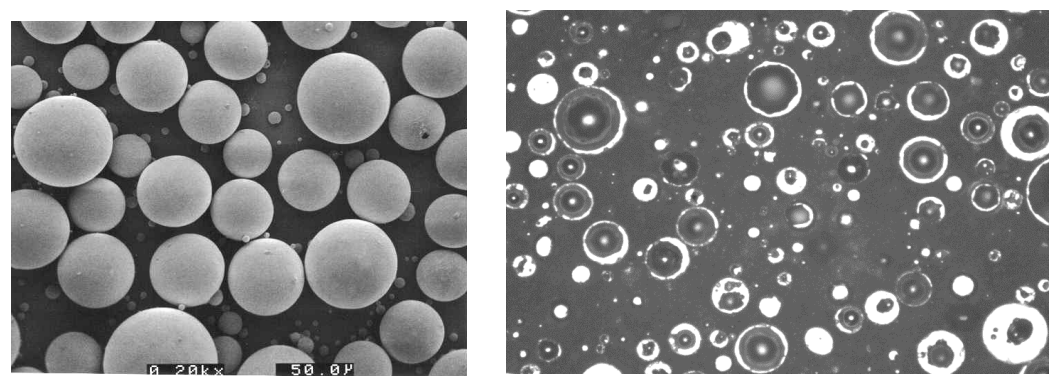

(a) 

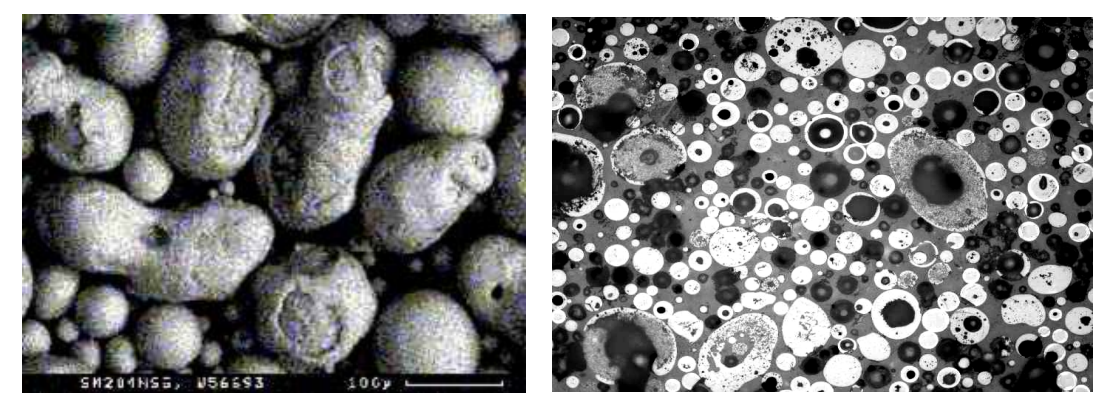

(b)

Fig. 9. External and cross-sectional views of particles in the $\mathrm{ZrO}_{2}$ powders: (a) - powder obtained by the present authors, (b) - commercially available $\mathrm{ZrO}_{2}$ powder.

An important characteristic of hollow powders is the shell thickness of the microsheres. Within each of the fractions of the $\mathrm{ZrO}_{2}$ powder obtained with the use of the two-jet plasma torch, we attempted separation of particles with shell thicknesses falling into a certain range; in particular, we tried to organize withdrawal of dense particles. For convenience, we now introduce a new quantity called the effective density of particles $\rho_{\text {eff }}$. This density presents the ratio of the particle mass $m_{p}$ to the particle volume $V_{p}$ :

$\rho_{\text {eff }}=\frac{m_{p}}{V_{p}}=\rho_{Z r O_{2}}\left[1-\left(1-2 \delta_{p}\right)^{3}\right]$,

where $\rho_{\mathrm{ZrO}_{2}}=5.6 \mathrm{~g} / \mathrm{cm}^{3}$ is the true density of zirconia particle.

A most reliable method for separating dense from hollow particles is hydrostatic separation, or floatation: particles with an effective density $\rho_{\text {eff }}$ greater than the liquid density $\rho_{l}$ descend to the vessel bottom, whereas particles with a lesser density come to the surface. As for the $\mathrm{ZrO}_{2}$ powder under consideration, this implies that, for the separation process, a liquid with a density not less than $\rho_{l}=3 \mathrm{~g} / \mathrm{cm}^{3}$ is required. One of the methods to increase a density of liquids is using strong solutions of readily soluble, high-density salts. We attempted preparation of a solution of dihydrated potassium iodide in water $\left(\mathrm{BaI}_{2} \cdot 2 \mathrm{H}_{2} \mathrm{O}\right.$, molar mass $426 \mathrm{~g} / \mathrm{mole}$, solubility in water at $40^{\circ} \mathrm{C} 322 \mathrm{~g}$ per $100 \mathrm{~g}$ of water). At room temperature, we were able to reach a density $\rho_{l}=2.21 \mathrm{~g} / \mathrm{cm}^{3}$. In using a denser liquid, bromoformum $\left(\mathrm{CHBr}_{3}\right.$, density $\left.\rho_{l}=2.89 \mathrm{~g} / \mathrm{cm}^{3}\right)$, in each fraction only an insignificant fraction of particles (not more than 1-2\%) were found to ascend to the surface; this means that in the majority of particles the wall thickness was greater than 0.11 . This method can also be used in treating less dense materials, for instance $\mathrm{SiO}_{2}$, whose true density is $2.3 \mathrm{~g} / \mathrm{cm}^{3}$.

The fraction-average relative shell thickness of the particles $\bar{\delta}_{p}$ was calculated from their measured mean effective density $\bar{\rho}_{\text {eff }}$ :

$\bar{\delta}_{p}=\frac{1}{2}\left(1-\sqrt[3]{1-\frac{\bar{\rho}_{e f f}}{\rho_{\mathrm{ZrO}_{2}}}}\right)$.

The mean effective density was determined as follows. A volume $V$ of water was poured into a test tube, graduated in terms of volume, and then the mass of the poured water was determined. Next, the hollow $\mathrm{ZrO}_{2}$ powder was added to the liquid; the powder was settled to the bottom of the test tube. Then, the change in the tube mass, $\Delta m$, and the change in the liquid volume, $\Delta V$, were measured. The mean effective density of the powder was then calculated as $\bar{\rho}_{\text {eff }}=\Delta m / \Delta V$. In our measurements, the mass of the powder loaded into the test tube was 10 grams, and the volume change was $3 \mathrm{ml}$; this, at a 0.01 -g inaccuracy of mass measurements and $0.1-\mathrm{ml}$ inaccuracy of volume measurements, guaranteed a 3-\% accuracy in determination of effective density and 4-\% accuracy in determination of wall thickness. 
Measured values of the mean effective density of hollow $\mathrm{ZrO}_{2}$ particles, and also measured values of the relative shell thickness in particles of various fractions are summarized in Table 1.

Table 1. Measured shell thicknesses of $\mathrm{ZrO}_{2}$ hollow microspheres.

\begin{tabular}{|c|c|c|c|c|c|c|}
\hline$D_{p}, \mu \mathrm{m}$ & $45-50$ & $50-56$ & $56-63$ & $63-71$ & $71-80$ & $81-90$ \\
\hline $\bar{\rho}_{e f f}, \mathrm{~g} / \mathrm{cm}^{3}$ & 4.64 & 3.76 & 4.27 & 3.92 & 3.43 & 4.19 \\
\hline $\bar{\delta}_{p}$ & 0.22 & 0.15 & 0.19 & 0.17 & 0.14 & 0.18 \\
\hline
\end{tabular}

\subsection{Processing of mechanocomposite particles}

Our first model experiments on plasma spraying of coatings from metal powders given a preliminary high-energy mechanoactivation (MA) treatment and modified with high-melting ultra-fine particles (MA+M), which were reported in [9-11], have allowed us to obtain, at all other conditions being identical, coatings whose microstructure and properties substantially differed from those of coatings sprayed from standard powders.

Yet, until recently it was not possible to give a detailed explanation to the results obtained because of lack of experimental data concerning the behavior in plasma jet, and subsequent interaction with substrate, of initial mechanically activated powder particles modified with high-melting nanoparticles.

It is a well-known fact [12] that coatings obtained by gas thermal (and also plasma) spraying are formed from individual splats, or flattened and solidified melt droplets, laid one by one onto the base. With the aim to examine the effect of mechanical activation of initial powder and its modification with high-melting ultra-fine particles on the treatment of particles in a plasma jet, and also on the formation of splats and coatings, we performed model experiments in which, as the initial powder, a standard CoNiCrAlY (Amdry-9951) powder was employed, normally used in spraying as bond layer of thermal barrier coatings, and, as the modifying additives, titanium carbide nanoparticles were used $[13,14]$.

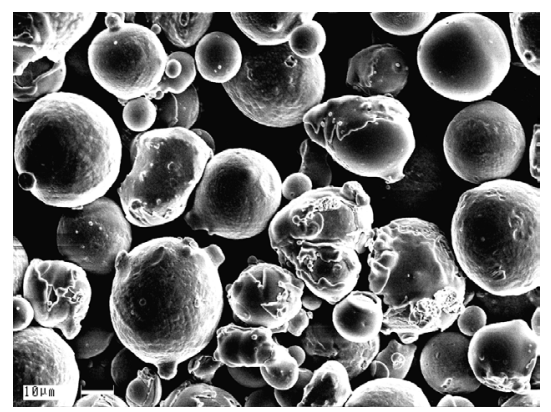

(a)

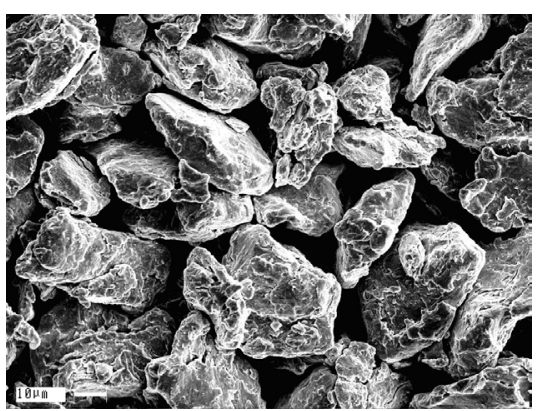

(b)

Fig. 10. External appearance of the CoNiCrAlY powders: initial AMDRY-9951 powder (a), powder obtained by joint mechanical activation of the AMDRY-9951 powder with ultra-fine TiC particles in an AGO-2 planetary mill [15] (b).

Figure 10 shows SEM photographs illustrating the morphology of the initial and processed $(\mathrm{MA}+\mathrm{M}) \mathrm{CoNiCrAlY}$ powders. It was found that, during the high-energy mechanical pre-treatment of the initial powder in an AGO-2 centrifugal-planetary mill [15], disintegration of initial particles into fragments and subsequent adsorption of working-gas molecules (air, argon, etc.) on the newly formed chemically active surface of the fragments, occurred. During further processing, simultaneous volume mixing, disintegration, and aggregation of fragments proceeded; those processes led to the formation of gas-rich 
particles with a large specific surface and high porosity. In combined mechanical activation (MA) of the initial powder with high-melting nanoparticles (MA+M), an additional factor acting to increase the gas content of obtained mechanocomposite particles was chemical activity of the nanoparticles.

Subsequent treatment of the MA/MA+M metal and alloy powders in plasma resulted in the formation of hollow spherical droplets, which then solidified into hollow microspheres (Fig. 11, a). The splats formed from the hollow droplets impinging onto substrate under plasma-spray conditions (Fig. 11, b) exhibited a more stable formation pattern in comparison with dense particles of the same mass; this ensured a more continuous coating/substrate interface and, hence, improved functional properties of sprayed coatings [16-18].

1

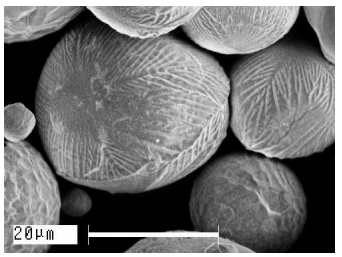

(b)

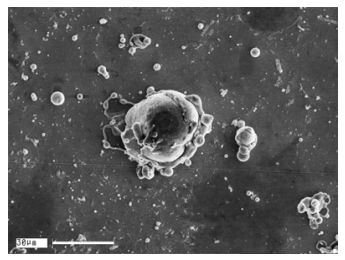

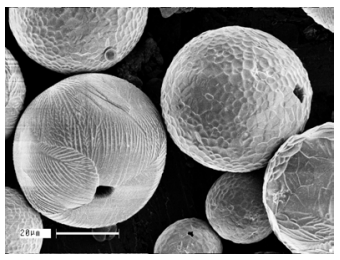

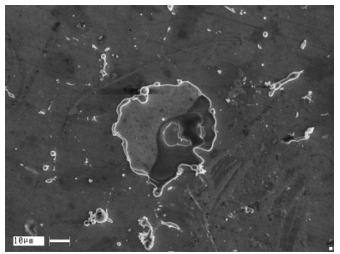

3
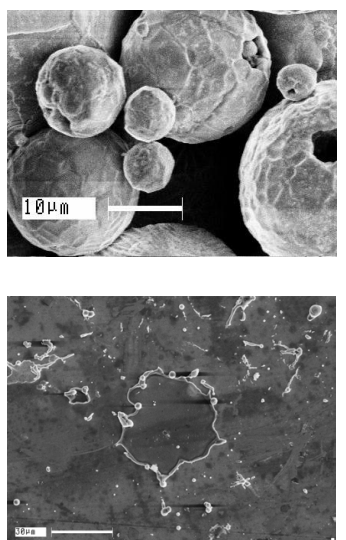

Fig. 11. Morphology of CoNiCrAlY particles processed in plasma and then quenched in a liquid (a) and that of CoNiCrAlY particles after their impingement onto a polished stainless-steel substrate (b). 1 - initial powder; 2 - after mechanical activation; 3 - after mechanical activation and modification with $\mathrm{TiC}$ nanoparticles.

\subsection{Processing of gas-rich metal and alloy particles}

As it was noted above, the major requirements for obtaining hollow microspheres are a sufficiently high gas content of the initial powder particles to be treated in plasma, and also a sufficient rate of the heat flux from plasma to particles providing for a gradient heating of particles till the moment the material starts melting at the surface, i.e., for the condition $L_{q m} / R_{p}=\lambda_{p}^{(s)}\left(T_{p m}-T_{p 0}\right) / q R_{p}<<1$.

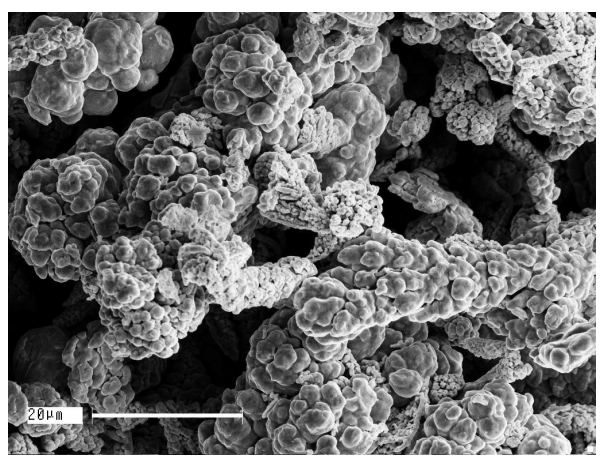

Fig. 12. External appearance of the initial PNE-1 nickel powder.
In conducting experiments, as the model metal powder, a PNE-1 nickel powder with a developed surface was used; this powder was formed by 1-3 $\mu \mathrm{m}$ sized microparticles (Fig. 12). Yet, in contrast to the agglomerated $\mathrm{ZrO}_{2}$ powder, in the PNE-1 powder the metal microparticles forming individual agglomerates sized 45-50 $\mu \mathrm{m}$ (after sizing) with porosity $p=0.05$ were tightly joined together. The specific surface area of the powder was $S_{\text {specific }}=2.21 \mathrm{~m}^{2} / \mathrm{g} \quad ; \quad$ this value 
provided for a high gas content of the particles.

As it was noted above, an effective method to increase the gas content of metal powders is mechanical activation; for instance, processing of the PNE-1 nickel powder in an AGO-3 planetary mill [15] (acceleration $80 \mathrm{~g}$, process duration 15 seconds) ensured an absorbed gas-to-material mass ratio $m_{g} / m_{p}=2 \cdot 10^{-3}$. Due to plasma treatment and subsequent quenching in water, the porosity of the powder was at a level of $p=0.05-0.08$.

In spite of the fact that the gas content of the initial and mechanically activated powders was one order of magnitude greater than that of the $\mathrm{ZrO}_{2}$ agglomerates, we failed to obtain hollow particles from those powders in argon plasma; the particles obtained were spheres with a structured surface, sometimes with holes observed in it. Figure 13 shows SEM photos that illustrate the external appearance and cross-sectional view of PNE-1 powder particles treated in plasma. Examination of cross-sectional cuts of the particles showed that the particles contained, instead of a single gas cavity, a number of volume-distributed large pores (see Fig. 13, b). As a result of treatment in plasma, the porosity of the powder has increased by several times, to $p=0.44$. It is worth noting that, as it was shown in $[19,20]$, composite particles obtained by SHS and spheroidized in plasma displayed a similar morphology.

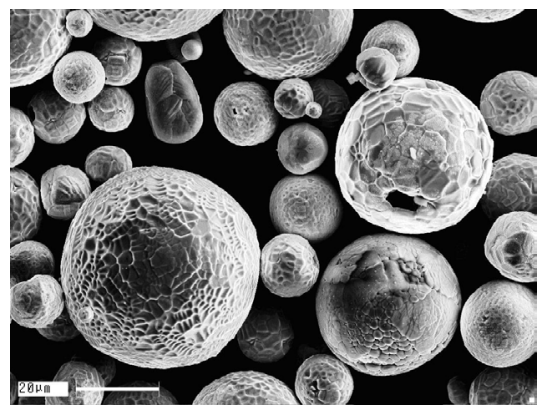

(a)

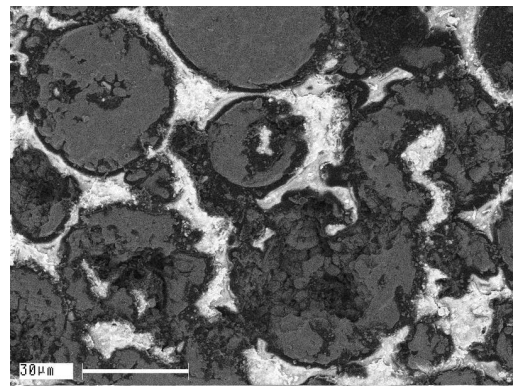

(b)

Fig. 13. The PNE-1 nickel powder treated in a plasma jet (argon plasma, thermal power $P_{T}=21 \mathrm{~kW}$, processing capacity $G_{N i}=5 \mathrm{~kg} /$ hour ): (a) - external appearance, (b) - cross-sectional view.

The factors leading to that, as a result of processing of the metal powder in argon plasma jet, no hollow spheres were formed were: (i) a high thermal conductivity of nickel (Biot number $\mathrm{Bi}<<1$ ) and (ii) a low rate $q$ of the heat flux from argon plasma to particles. It can be shown that, in the latter case, the condition $t_{a} / t_{q m}=R_{p} q / \lambda_{p}^{(s)}\left(T_{p m}-T_{p 0}\right)>1$ was not met. As a result, a uniform (gradientless) heating of particles to the melting point took place, leading to that the particles melted uniformly throughout their volume; already before the melting, a considerable portion of the gas mass initially contained in the particles could escape into environment as a result of an intense thermal expansion of the gas and its leaving the agglomerates. As a result, in the volume-melted particles the initial pores formed, instead of a central gas cavity, a system of volume-distributed gas cavities.

On the contrary, in the case of processing of agglomerated $\mathrm{ZrO}_{2}$ particles in a nitrogen or air plasma jet, due to a low thermal conductivity of the oxide and a greater rate of the heat flux from plasma to particles the particles underwent a gradient heating during which a melt surface film formed on the surface of the particles. As a result, a considerable gas mass remained arrested inside the particle, the melting front moved from the surface into depth, thus forcing the gas cavities towards the particle center and causing their merging there.

\subsection{Processing of metal hydroxide particles}

One more production process of hollow powders is exemplified by plasma treatment of aluminum hydroxide particles 70 to 120 micrometers in diameter with 12 to $17 \mathrm{wt} \%$ of 
chemically bound water. The treatment was performed in an air plasma jet flowing out in a quasi-laminar regime out of a 50-kW cascaded plasma gun.

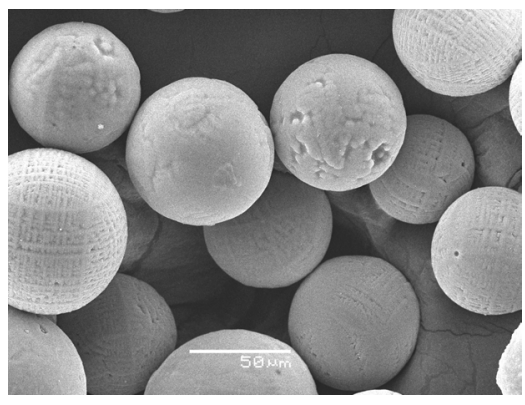

(a)

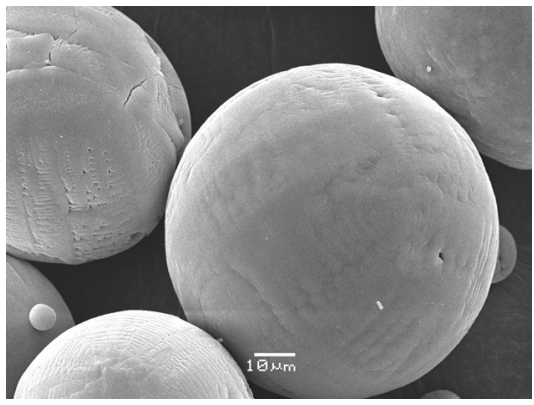

(b)

Fig. 14. SEM photographs of the synthesized hollow powder of microspherical aluminum oxide taken at different magnifications.

As a result, a microspherical aluminum oxide was obtained, which, as SEM data show, consisted of particles 70 to 120 micrometers in diameter shaped as hollow spheres with a smooth or ribbed surface [4] (see Fig. 14).

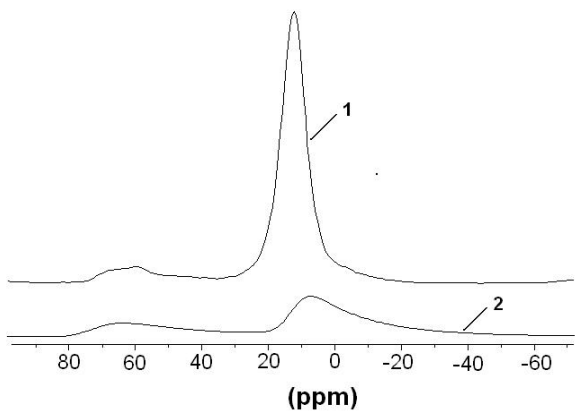

Fig. 15. Solid-state NMR spectra of ${ }^{27} \mathrm{Al}$ in the powder made up by hollow corundum microspheres. Primary phase $-\alpha-\mathrm{Al}_{2} \mathrm{O}_{3}(1)$, $\gamma-\mathrm{Al}_{2} \mathrm{O}_{3}$ component (about 1 wt.\%) (2).
Measured solid-state MNR spectra of ${ }^{27} \mathrm{Al}$ showed (see Fig. 15) that, in such a microspherical aluminum oxide powder, the aluminum atoms resided in the octahedral surrounding of oxygen atoms with a high degree of crystal ordering. According to derivatographic data, the obtained microspherical aluminum oxide contained $1 \%$ of low-temperature aluminum oxide phases and no physically bound water. Thus, the sample was 99 wt. $\%$ of $\alpha-\mathrm{Al}_{2} \mathrm{O}_{3}$ (corundum) having no developed surface.

\subsection{Suspension plasma treatment}

In several recent years an active interest has been shown to suspension plasma spraying (SPS), a process in which a liquid containing suspended nano- and submicrometer particles of spray material is injected under pressure into a plasma flow [22-25].

We were first to show that, under such conditions, formation of hollow particles was possible.

In [26] it was shown possible to obtain hollow microspheres several ten micrometers in diameter by processing an agglomerated $\mathrm{SiO}_{2}$ powder in plasma.

The starting powder was a quartz glass powder that was mechanically treated in a high-energy AGO-2 planetary mill. The external appearance of the initial powder is shown in Fig. 16; here, the submicrometer particles form agglomerates sized predominantly 10 to $20 \mu \mathrm{m}$. On introduction of the powder into a liquid, the agglomerates disintegrated into separate submicrometer particles. BET measurements showed that the specific surface area of the powder was $S_{\text {specific }}=22.72 \mathrm{~m}^{2} / \mathrm{g}$, this value yielding for the effective diameter of the spherical particles a value of $100 \mathrm{~nm}$.

Here, the traditional method for injection such an agglomerated powder into a high-temperature, high-velocity zone of a plasma jet through an injector with the help of a transporting gas could not be implemented because the effective density of the particles was 
low and the flowability of the powder, poor. An alternative was treatment in plasma of a atomized suspension comprising a liquid and nano- and submicrometer solid particles suspended in the liquid [26]. To this end, a special injector was designed (see Fig. 17), which was used to introduce a powder suspension in water, initially contained in a pressure vessel, into the plasma jet. On atomization, the liquid jet disintegrated into droplets several ten micrometers in size, which contained quartz glass ultra-fine particles suspended in the liquid. The adopted conditions allowed the formation, after evaporation of droplets, of agglomerates of initial particles, whose subsequent heating and melting led to the formation of hollow $\mathrm{SiO}_{2}$ particles.

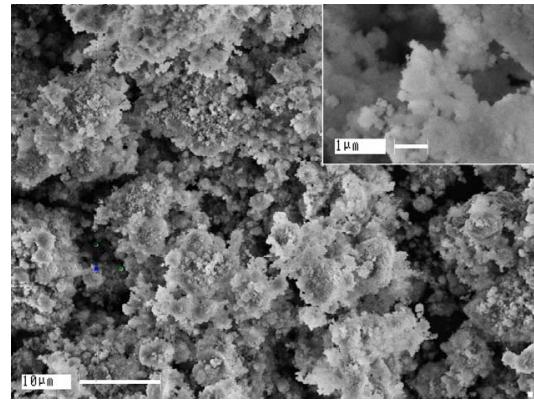

Fig. 16. External appearance of the initial $\mathrm{SiO}_{2}$ powder.

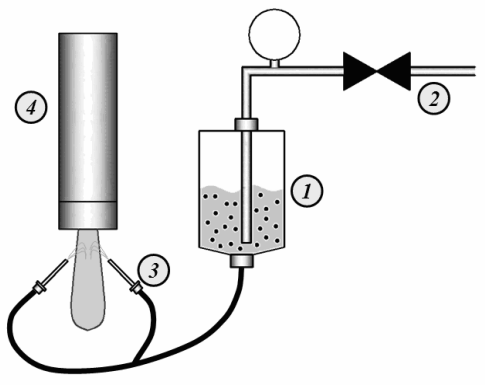

Fig. 17. Diagram of the suspension injector: 1- suspension vessel, 2-high-pressure gas line, 3-injectors, 4-plasma gun.

A hollow microspherical $\mathrm{SiO}_{2}$ powder was obtained with the help of a plasma torch operated at $76-\mathrm{kW}$ electrical power, with the flow rate of plasma-forming air $1 \mathrm{~g} / \mathrm{s}$, water suspension discharge $1.1 \mathrm{~g} / \mathrm{s}$, and mass content of powder in water $25 \mathrm{~g} / \mathrm{l}$.

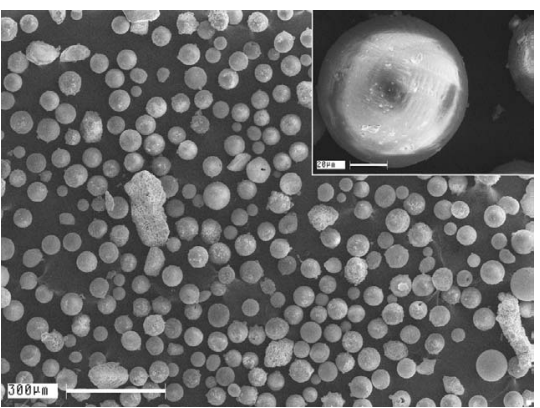

(a)

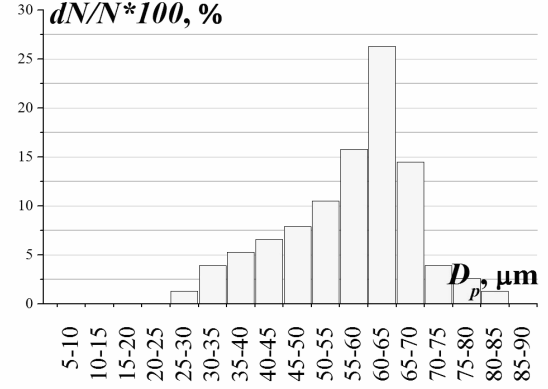

(b)

Fig18. External view (a) and size distribution (b) of $\mathrm{SiO}_{2}$ particles processed in plasma jet.

As it is seen, the processed powder contained no particles smaller than $25 \mu \mathrm{m}$ in diameter, and the majority of spheres in it had sizes 40 to $70 \mu \mathrm{m}$ (see Fig. 18). Measurements of the effective density of the obtained powder showed that the powder porosity was $47 \%$, yielding for the mean relative shell thickness of hollow particles a value $\bar{\delta}_{p}=0.11$.

Thus, we have developed a combined process incorporating two production stages in obtaining hollow particles, the formation of agglomerates from fine material grains, and subsequent formation of hollow droplets. On atomization, the suspension jet formed droplets several ten micrometers in size, which comprised submicron $\mathrm{SiO}_{2}$ particles. On evaporation of the liquid, there formed agglomerates of initial particles and, then, hollow $\mathrm{SiO}_{2}$ droplets emerged according to the scenario described above. The presence of irregularly shaped particles sized $150-250 \mu \mathrm{m}$ was indicative of the fact that, during plasma processing, large drops formed, which, as they underwent an intense evaporation, yielded agglomerates, which underwent sintering yet had not enough time to get melted. 


\section{Conclusions}

In the present paper, we gave an overview of our studies aimed at development of plasma processes for obtaining hollow microspherical metal, alloy, and oxide ceramic powders. It was shown that thermal plasma can be used in production of such powder materials from initial powders whose particles present porous agglomerates obtained by (i) spray drying of materials, (ii) mechanical activation of powder materials in a high-energy planetary mill, (iii) electrolytic deposition, and (iv) spraying of suspensions with contained nano- and submicrometer-sized particles. Besides, with the example of aluminum oxide and hydroxide, we proved it possible to obtain hollow corundum microspheres. The main conditions for production of hollow particles were formulated: sufficient gas content in feedstock material and density of heat flux.

A simple theoretical grounds of involved processes are presented, allowing one (i) to formulate requirements to the plasma flow for guaranteed production of hollow microspheres from processed agglomerated particles (ii) and to predict the behavior of hollow droplets formed in the plasma flow with the aim of controlling the particle size and shell thickness.

The results of the present work may prove useful for specialists involved in the high-temperature synthesis, and application, of various-purpose powders, including plasma processing of powder materials.

The results overviewed in the present article were obtained in the framework of Program of Prezidium of Russian Academy of Sciences No. 11 on 2009-2011 (Project № 7).

\section{References}

1. M.F. Zhukov, O.P. Solonenko, High-temperature dusted jets in powder materials treatment processes, V.E. Nakoryakov Ed., Novosibirsk, ITP SB RAS, 1990,516 P. (in Russian).

2. M.A. Maurakh, B.S. Mitin, Liquid refractory oxides, Moscow, Metallurgiya, 1979, 288 P. (in Russian).

3. N.B. Vargaftik, Handbook on thermophysical properties of gases and liquids, Moscow, Nauka, 1972, 720 P. (in Russian).

4. O.P. Solonenko, A.V. Smirnov, I.P. Gulyaev, Spreading and solidification of hollow molten droplet under its impact onto substrate: computer simulation and experiment, Proc. of $4^{\text {th }}$ Int. Conf on Flow Dynamics, 26-28 September 2007, Sendai, Japan, P. 325-332.

5. O.P. Solonenko, A.V. Smirnov, I.P. Gulyaev, Hollow droplets microexplosive thermal spraying: fundamentals, Proc. of International Thermal Spray Conf., 2-4 June 2008, Maastricht, Netherlands.

6. O.P. Solonenko, I.P. Gulyaev, A.V. Smirnov, E.V. Kartaev, Plasma processing of spray-dried YSZ powder and formation of splats from hollow molten particles impinging onto substrate, Proc. of 18th Int. Symposium on Plasma Chemistry, 26-31 August 2007, Kyoto, Japan, P.637-640.

7. O.P. Solonenko, A.V. Smirnov, I.P. Gulyaev, Spreading and solidification of hollow molten droplet under its impact onto substrate: computer simulation and experiment, Complex Systems: The 5th Int. Workshop on Complex Systems (26-28 September 2007, Sendai, Japan), American Institute of Physics, Melville, New York, 2008, Vol. 982, P.561-568.

8. O.P. Solonenko, I.P. Gulyaev, A.V. Smirnov, Plasma technologies of production, treatment and spraying of powders consisting of hollow particles, Proc. of 9th Int. conf. "Films and Coatings", May 26-29 2009, St.-Petersburg, Russia, P. 206-210 (in Russian).

9. O.P. Solonenko, A.N. Cherepanov, V.N. Popov et al., Plasma spraying of resistant coatings of mechanically activated and modified with nano-particles powder materials, Surface layers and interface regions in heterogenius materials, V.E. Panin Ed., Novosibirsk, SB RAS Publ., 2006, P. 418-460(in Russian).

10. O.P. Solonenko, A.N. Cherepanov, V.F. Kosarev et al., Development of combined 
production technologies of promising powder materials, functional coatings and surface layers with regulated nano- and microstructure, Proc. of science session of Presidium of Siberian Branch of RAS, December 22 2006, Novosibirsk, SB RAS Publ., 2007, P. 186-198 (in Russian).

11. O.P. Solonenko, A.N. Cherepanov, V.V. Marusin, V.A. Poluboyarov, Combined technologies of promising powder materials production, coatings deposition and surface layers with regulated nano- and microstructure hardening, Heavy Engeneering, 2007, Vol. 10, P. 10-13 (in Russian).

12. V.V. Kudinov, Plasma coatings, Moscow, Nauka, 1976, 189 P. (in Russian).

13. O.P. Solonenko, V.A. Poluboyarov, A.N. Cherepanov, I.P. Gulyaev, A.E. Lapin, Peculiarities of plasma treatment and spraying of mechanically activated metal and metal alloy powders modified with ultra-fine refractory particles, Proc. of 18th International Symposium on Plasma Chemistry, 26-31 August 2007, Kyoto, Japan, 4 P.

14. O.P. Solonenko, V.A. Poluboyarov, A.N. Cherepanov, I.P. Gulyaev, A.E. Lapin, Peculiarities of plasma treatment and spraying of metal and alloy powders mechanically activated and modified with refractory nanoparticles, Proc. of 8th Int. Conf. "Films and Coatings", May 22-25 2007, St.-Petersburg, Russia, P. 18-21 (in Russian).

15. E.G. Avakumov, A.R. Potkin, O.I. Samarin, Planetary-type mill, Patent of Russian Federation № 975068, 1982 №43.

16. O.P. Solonenko, I.P. Gulyaev, A.V. Smirnov, Plasma processing and deposition of powdered metal oxides, consisting of hollow spherical particles, Technical Physics Letters, 2008, Vol. 34, No. 12, pp. 1050-1052.

17. O.P. Solonenko, V.A. Poluboyarov, A.E. Lapin, Z.A. Korotaeva, A.N. Cherepanov, Potentials of powders mechanical activation for spraying of thermal coatings sublayers, Proc. of Russian Sci.-Tech. Conf. "Ultra-dispersed powders, nanostructures, materials: production, properties, application”, September 28-29 2006, Krasnoyarsk, P. 266-269 (in Russian).

18. O.P. Solonenko, V.A. Poluboyarov, A.E. Lapin et al., Mechanical chemical nano-dispersions for improvement of sprayed sublayers of thermal coatings on gas turbines blades made of nickel superalloy, Proc. of 4th Int. Technological Congress "Military hardware, armament ond modern technologies in military and civil production", June 4-9 2007, Omsk, part 2, P. 399-405 (in Russian).

19. V.E. Ovcharenko, V.A. Klimyenov, O.V. Lapshin et. Al., Plasma processing and spraying of composite powders having a microdispersed inner structure, Proc. of $3^{\text {rd }}$ European Congress on Thermal plasma Processes, 19-21 September 1994, Aachen, Germany, P. 395 - 403.

20. P.Yu. Gulyaev, I.V. Milyukova, O.P. Solonenko, I.P. Gulyaev, Phase-structural changes in powdered SHS-materials during plasma spraying, Izvestia VUZov, Physics, 2007, Vol. 9, appendix, P. 349-352.

21. O.P. Solonenko, A.M. Leonchikov, F.V. Nedosedkin, E.V. Efimova, Powdered aluminium alpha-oxide, production method and product, Patent on invention of Russian Federation № 2386589, 17.09.2008.

22. J. Fazilleau, et al., Phenomena involved in suspension plasma spraying. Part 1: Suspension injection and behavior, Plasma Chem. Plasma Process,2006, №.26, P. 371-391.

23. J. Fazilleau, et al., Phenomena involved in suspension plasma spraying. Part 2: Zirconia particle treatment and coating formation, Plasma Chem. Plasma Process, 2006, №.26, P. 393-414.

24. O. Tingaud, A. Grimaud, A. Denoirjean, et al., Suspension plasma-sprayed alumina coating structure: operating parameters versus coating architecture, J. Therm. Spray Tech., 2008, Vol. 17(5-6), P.662-670.

25. F. Tarasi, M. Medraj, A. Dalatabadi, et al.,Effective parameters in axial injection suspension plasma spraying process of alumina-zirconia ceramics, J. Therm. Spray Tech.,2008, Vol. 17(5-6), P.685-691.

26. O.P. Solonenko, A.V. Smirnov, A.M. Leonchikov, I.P. Gulyaev, Oxide powder processes based on dc and twin plasma torches, Proc. of $6^{\text {th }}$ Intern. Symp. on the Basic and Application of Plasma Technology, 14-18 December 2009, Hsinchu, Taiwan, 4 p. 